h 0 9 $\begin{aligned} & \text { Haute école de gestion de Genève } \\ & \text { CRAG - Centre de Recherche Appliquée en Gestion } \\ & \text { Cahier de recherche }\end{aligned}$

Seven Reasons to Use Carbon Pricing in Climate Policy

\author{
Andrea Baranzini, Jeroen van den Bergh, \\ Stefano Carattini, Richard Howarth, \\ Emilio Padilla \& Jordi Roca
}

Cahier N ${ }^{\circ}$ HES-SO/HEG-GE/C--15/4/1-CH

2015 


\title{
Seven Reasons to Use Carbon Pricing in Climate Policy
}

\author{
Andrea Baranzini ${ }^{1}$, Jeroen van den Bergh ${ }^{2,3,4}$, Stefano Carattini ${ }^{1,5}$, \\ Richard Howarth ${ }^{6}$, Emilio Padilla7, Jordi Roca ${ }^{8}$
}

\footnotetext{
${ }^{1}$ Haute Ecole de Gestion Genève, University of Applied Sciences Western Switzerland (HES-SO)

2 Institute of Environmental Science and Technology, Universitat Autònoma de Barcelona

${ }^{3}$ ICREA, Barcelona

${ }^{4}$ Institute of Environmental Studies \& Faculty of Economics and Business Administration, VU University Amsterdam

${ }^{5}$ Grantham Research Institute on climate change and the environment, London School of Economics and Political Science (LSE)

${ }^{6}$ Environmental Studies Program, Dartmouth College

7 Department of Applied Economics, Universitat Autónoma de Barcelona

${ }^{8}$ Faculty of Economics and Business, University of Barcelona
}

Cahier de recherche

\section{November 2015}

\begin{abstract}
The idea of a global carbon price has been a recurrent theme in debates on international climate policy. Discarded at the Conference of Parties (COP) of Copenhagen in 2009, it remained part of deliberations for a climate agreement in subsequent years. Unfortunately, there is still much misunderstanding about the reasons for implementing a global carbon price. As a result, ideological and political resistance against it prospers. Here we present the main arguments in favor of a carbon price to stimulate a fair and well-informed discussion about climate policy instruments. This includes arguments that have received surprisingly little attention so far. It is stressed that a main reason to use carbon pricing is environmental effectiveness, so not only economic efficiency (including the special case of cost-effectiveness). In addition, we provide ideas on how to implement a uniform global carbon price, whether using a carbon tax or emissions trading.
\end{abstract}

Keywords Climate policy; Carbon pricing; Carbon tax; Emissions trading 


\section{Introduction}

In the aftermath of COP21 in Paris, countries will have to turn pledges into effective policies, to guarantee that their promises about reduction of greenhouse gas emissions are realized. It is easy to underestimate this challenge. We argue that ambitious targets can only be met by using the instrument of carbon pricing, with the ultimate aim of a uniform global carbon price. All alternative options are likely to lead to insufficient, ineffective and very costly abatement activities, thus undercutting the pledge and review system, as well as jeopardizing the potential for more ambitious targets in the future. Our society is at a turning point. Imprudent policy design could have extremely far reaching consequences, not least because of the real chance of dangerous climate change.

However, many observers, notably social scientists, are critical of carbon pricing, even though often without being well informed about its precise impacts and benefits. Here we argue that the main reason for it is not only efficiency or cost-effectiveness, but environmental effectiveness. We provide many reasons, which have been largely overlooked in critical writings on carbon pricing.

\section{Characteristics of climate change and implications for policy instruments}

Climate change possesses several characteristics that must be accounted for in the formulation of climate policies to guarantee their effectiveness. Sources of anthropogenic emissions are diverse and cover all economic sectors. Emissions arise from both production and consumption, including resource extraction and waste management activities. Hence, abatement costs are very heterogeneous. In addition, greenhouse gas (GHG) emissions accumulate in the atmosphere with residence times stretching from centuries to millennia. Therefore, abatement incentives should be dynamic, i.e. responsive to economic and technological change, and last through time. Moreover, the location of GHG emissions does not have an impact on climate change. As a result, the distribution of GHG abatement efforts can be uneven across space. Another feature of climate change is that there is no simple set of unproblematic end-of-pipe solutions - witness the debate about carbon capture. It follows that it is necessary to abate GHG emissions through a wide range of options, including changes in behavior (e.g. using less energy), structural change in the composition of the economy (dirty versus cleaner sectors and products, and different input mixes in production), more energy- 
efficient technologies, and low-carbon (notably renewable) energy production. Finally, particularly challenging for international negotiations is that abatement activities are costly and constitute global public goods; that is, others can benefit from them without undertaking any effort. It is thus necessary to coordinate actions to avoid free-riding behavior and international carbon leakage. Therefore, a worldwide policy is needed to avoid unwanted transboundary displacement of emissions and to ensure fair economic competition between countries.

We argue that carbon pricing supported by a climate agreement is able to address these characteristics of climate change. This becomes clear by considering seven unique advantages of it, as explained hereafter.

\section{Seven arguments in favor of international carbon pricing}

Carbon pricing affects carbon emissions by penalizing energy sources in proportion to their carbon content. It is easily applicable to emissions coming from energy use, but can be extended to emissions arising from land use changes and other sources. The following are the most important arguments in favor of carbon pricing:

1. In accordance with the Polluter Pays Principle, carbon pricing changes relative prices. As a consequence, when making decisions that cause carbon emissions, firms and consumers will not just take into account their private costs and benefits, but will automatically account, without necessarily being aware of it, for the social costs due to (direct and indirect) carbon emissions generated in every phase of the product life cycle from resource to waste. The entire economy can then become less carbon-intensive, since all consumers and producers will adjust their decisions to prices corrected for the climate externality. The carbon price should, though, be high enough to induce the required adjustments leading to the emissions abatement objective.

2. Compared to other types of instruments, carbon pricing can address the vast heterogeneity of greenhouse gas emitters, thus helping to minimize the cost of pollution control. Heterogeneity might result from firms having different production (and thus emitting) technologies, sizes, organizations, etc., which translates into distinct marginal pollution abatement costs. In theory assuming perfect information and substantive rationality - all polluters should choose that level of 
emissions abatement for which the associated marginal cost equals the carbon price. With a unique carbon price, the marginal abatement costs would then be identical among all polluters, which implies that a particular abatement goal will be met at the least global cost. No other instrument than pricing is able to realize this goal. However, since polluters are not always perfectly aware of relevant abatement technologies and associated costs, one may expect that the actual global cost will not reach the lowest level. Nevertheless, empirical research suggests that reliance on nonprice policy instruments can lead to considerably higher abatement costs in the absence of price incentives (Fischer and Newell 2008). The reason is that such instruments are less effective in covering diverse sources of emissions (e.g. technical standards cannot be applied subtly to all millions of technologies and products in the world). Instead, a carbon price is a systems-approach that spans over all sources of emissions.

3. Carbon pricing contributes to dynamic efficiency. That is, through time it stimulates research and development, innovation and adoption of new technologies emitting less carbon. By increasing the cost of carbon-emitting technologies and activities, carbon pricing provides a financial incentive for consumers and producers to invest in technologies reducing emissions. Empirical evidence suggests indeed a positive relationship between higher energy prices and the development of (green) innovation technologies (Ambec et al. 2013). Compared to emission or technology-based standards, carbon pricing can provide a higher economic incentive (benefit) for adoption of, and R\&D on, improved abatement technologies (Jaffe and Stavins 1995). Carbon pricing is thus an important element of a policy package aimed at redirecting technical change towards the cleaner goods and ways of production (Acemoglu et al. 2012; Aghion et al. 2012). Indeed, without ecologically corrected prices one cannot expect innovation to be well oriented. This is underappreciated in many discussions about technological change and climate change, where pricing is downplayed as if innovation/diffusion subsidies and other innovation policies (information provision, stimulating cooperation between innovators) were sufficient. But carbon pricing and technology policy are largely complementary mechanisms and should thus both be part of a climate policy package.

4. Carbon pricing is the best instrument to control energy and carbon rebound in an effective way. 
Technological advances and improvements in energy efficiency tend to lead to a direct reduction in energy consumption. However, given the improved efficiency, the energy services - for instance, travelling by car - become cheaper. As a result, there is a general empirical consensus that people consume more energy than if energy efficiency improvements would not imply any change in behavior (Sorrell 2007). We argue that opportunities for such rebound effect would be limited if carbon pricing is in place (van den Bergh 2011). For example, it will discourage the more intense use of a more efficient and - without a carbon price - cheaper technology (e.g., a car with more fuel-efficient engine). In addition, it will discourage any money savings due to energy conservation to be spent on energy-intensive goods and services, as these will have a higher price due to carbon pricing. Empirical evidence suggests indeed that this so-called "re-spending rebound" is non-negligible (Antal and van den Bergh 2014). Carbon pricing would, moreover, not only reduce rebound with respect to the laissez faire, but also with respect to other policy options. While standards tend to control energy use and emissions only for a subset of technologies and associated services, carbon pricing can be regarded as a systems approach that discourages rebound consistently across all carbon-intensive goods and technologies (van den Bergh 2015). Finally, pricing will also assure that consumers can make a trade-off between the benefits and total (including environmental) costs of rebound resulting from their decisions. This assures that rebound associated with higher benefits than environmental damages will persist under carbon pricing. In other words, such rebound effects will not be eliminated by carbon pricing. Carbon pricing thus comes out as the best policy to deal with rebound, in terms of effective control and welfare effects.

5. An international carbon price covering all countries and sectors would ensure that there are no leakages - i.e. indirect unintended and unwanted production, consumption, innovation and diffusion effects that create more carbon emissions elsewhere. With consistently higher relative prices for all carbon-intensive products worldwide, there are no escape routes: all economic agents and thus countries will be stimulated to search for cheaper and thus less carbon-intensive alternatives. As suggested by Nordhaus (2015), if some countries would opt for not enforcing such a policy, free riding could be avoided - or reduced - by trade sanctions. Nordhaus proposes strong 
trade sanctions unrelated with the carbon content of trade. However, sanctions could also take the form of border carbon taxes on imports of non-complying countries, which, even though insufficient to ensure the incorporation of all countries in international climate policy, would contribute to address the problems of competiveness associated to carbon taxes.

6. Carbon pricing allows for flexibility and autonomy of choice, as emitters can freely change their behavior to reduce their costs. This means decentralization of policy, with associated low information needs. In addition, carbon pricing - instead of, e.g., eco-labeling - means that no separate life-cycle analysis is needed to account for all the carbon emissions of products and services over their life-cycle. Instead, firms will integrate carbon prices in existing cost-accounting systems of their products and services. This has the additional advantage that transaction costs are limited.

7. Even if one is environmentally conscious, it is virtually impossible to know which goods to buy and in what amounts to achieve one's environmental goals. Moreover, even though many people would like to contribute at a personal cost to a more responsible use of resources, such cooperative behavior may depend on the perception that others will or will not do the same (Ostrom 2009). The fact that an individual action alone has a negligible impact tends indeed to discourage people to undertake these voluntary actions. Moreover, many consumers are not particularly environmentally conscious in their purchase behavior, being sensitive to personally salient concerns, notably financial considerations, when making purchasing decisions. An effective climate policy should reach out to this majority: carbon pricing regulation will be capable of doing this as it naturally intervenes in the core element, namely pricing, of markets. It does so without assuming that people will act altruistically, showing voluntary environmentally benign behavior, or can handle much information about products, as in the form of eco-labels.

Even if a global carbon price existed, other climate change policies will still be necessary. In particular, given the public good characteristics and lock-in problems of technological innovation and R\&D activities, subsides or direct investment should be encouraged. Moreover, since in practice carbon pricing can hardly cover all GHG emissions, other policy instrument should be implemented. 
Finally, given informational failures and bounded rationality, carbon pricing can always be supplemented with mechanisms that aid households and businesses respond effectively to market signals and incentives (see Sanstad and Howarth 1994). Carbon pricing is thus not enough to confront all the challenges of climate change, which is not an argument against pricing and its unique and desirable properties, but a reason to complement it with additional policies.

\section{Practical implementation of international carbon pricing}

Two main instruments can achieve a unique worldwide carbon price: a global carbon tax and a global emissions trading system. While a carbon tax sets the carbon price directly through an administrative decision, an emissions trading system sets a cap on emissions and allocates the emission allowances between emitters, who can then trade them resulting in a carbon price. While they have different advantages and drawbacks, both instruments share the general favorable properties mentioned above. There is not an unambiguously better alternative, which explains why each option has its own advocates.

The most important difference between emission trading and carbon taxes concerns control of quantities versus price (Weitzman 1974). Emissions trading systems, by setting a cap, can guarantee the achievement of a given environmental objective. However, the price is uncertain. In contrast, in the case of carbon taxes, the price is known, but the level of emissions is uncertain. Emissions trading systems have been criticized for their volatility, which may be an important handicap for long-term investments, as these depend not only on current prices, but also on expectations about future prices. However, carbon prices in emissions trading systems do not necessarily have to be extremely volatile. Price floors and ceilings (so-called "safety valves") have been proposed to address the issue of volatility; one way to assure a minimum price takes the form of a mix system, namely a permanent tax and a permits market (Wood and Jotzo 2011).

\subsection{Implementing a carbon price through a tax}

There are two possible international carbon tax designs, both of which require an international climate agreement. One is a global carbon tax, the revenues of which would be collected centrally, e.g. 
through the UNFCCC Secretariat, and subsequently redistributed among countries, e.g. in relation to their demographic weight. Despite its political difficulty, this alternative would clearly be the preferred option, as it would imply a single worldwide carbon price. It would have positive international redistributive effects given the positive correlation between per capita GHG emissions and per capita income. A part of the revenues might be allocated to the provision of green funds financing environmental projects or adaptation measures in poorer countries. Despite economists have long advocated to fund only the socially most profitable investments, public acceptability studies show that using revenues from carbon taxes to finance environmentally beneficial projects can increase their social and political acceptability (Drews and van den Bergh, 2015).

The second alternative would be a tax raised by each country, while aiming at a single global carbon price through harmonized carbon taxes. By agreeing about this harmonized tax, countries would not be tempted to deviate from it for competitiveness or political-ideological reasons, which have been shown to substantially hamper the effectiveness of early efforts to implement carbon taxes (Baranzini and Carattini 2014). A drawback of harmonized taxes is that national governments would be less interested in reducing emissions with complementary policies, because any reduction of emissions would reduce fiscal revenues in contrast with a global tax (Hoel 1992). Thus, this second option should be judged as less attractive in environmental terms, but more viable politically.

\subsection{Implementing a carbon price through emissions trading}

An international emissions trading system could also take different forms. A truly global market would cover all individual emitters, giving rise to a single carbon price worldwide. This would assure cost-effectiveness of mitigation at a global level. However, creating such a global system of emission trading is very challenging in both political and institutional terms. Alternatively, an international treaty would fix a global emissions cap and then distribute allowances between countries, which could trade them fixing the global carbon price. In this case, countries could choose whether and how to introduce carbon pricing domestically as it would be desirable. However, similarly to carbon taxes, it could be easier to start with different emissions trading systems covering certain countries and regions (like the EU) and sectors, and integrate these globally in a subsequent stage. In the long run, this could 
lead to the coverage of all countries and sectors. Indeed, similarly to carbon taxes, various cap-andtrade systems are and have been developed in North America, Europe and Asia, forming a fertile basis for integration at a larger, global scale.

Setting rules of allocation of allowances among countries and emitters in each country is a major hurdle, since they reflect implicit ethical and political choices. The grandfathering approach used in many programs favors large emitters and penalize those who made mitigation efforts before the policy implementation. As a result, there is now broader support for initializing systems through auctioning permits, also as this would contribute to efficiency. However, while this is feasible for firms, as the EU ETS program has shown, its application to countries is less evident. As for carbon taxes, distributional concern would play in favor of either a redistribution of revenues from permit auctions based on the demographic weights of countries or the direct allocation of allowances on per capita basis. Hence, both could be progressive in terms of inter-country distribution and so address one of the criticisms to global carbon markets in particular and global carbon pricing in general.

\section{Conclusions}

We have presented seven reasons for using carbon pricing in climate policy:

1. It changes relative prices to reflect all direct and indirect $\mathrm{CO}_{2}$ emissions of products and services so that firms and consumers will automatically internalize the costs of global warming.

2. It minimizes the overall cost of pollution control as it accounts for differences (heterogeneity) between polluters in terms of abatement opportunities and costs.

3. It contributes to dynamic efficiency, because it provides continuous incentives for adoption and innovation of new technologies that emit less carbon dioxide.

4. It is the best instrument to control energy and carbon rebound in an effective way and avoiding undesirable welfare effects.

5. If it were to cover all countries and sectors, it would ensure that there are no leakages through international relocation of dirty industries and shifts in foreign trade patterns that merely replace carbon emissions from one countries to another. 
6. It implies decentralization of policy, with associated low information needs for regulators.

7. It relies on the empirical fact that when making purchase decisions, most consumers with regard to purchasing most products and services are more influenced by prices than by environmental concerns.

As a result, carbon pricing will be a very effective instrument, particularly because of reasons 1, 3, 4, 5 , and 7.

Many countries already have implemented policies to stimulate climate change mitigation, including carbon taxes and emissions trading schemes (World Bank 2014). However, these policies have been relatively ineffective as the levels of the policy instruments are often weak in the absence of a serious international climate agreement, to avoid negative implications for the respective countries' competitive position as well as carbon leakage (point 5).

Emissions pledges have been at the center of climate negotiations preparing for COP21 in Paris. We believe that negotiating around a single price will become easier as more countries get involved in carbon pricing and an increasing number of people become well informed about the unique advantages of carbon pricing. In view of these, we should remove ideological barriers against such a critical element of an effective climate policy package. We hope that the seven arguments in favor of carbon pricing presented here can convince readers that such an approach to climate policy deserves serious attention and debate. All alternative options are likely to result in considerably less effective, even though well-intended, ways of regulating emissions and likely will be unable to avoid dangerous climate change. 


\section{References}

Acemoglu, Daron, Philippe Aghion, Leonardo Bursztyn, and David Hemous. 2012. "The Environment and Directed Technical Change.” American Economic Review 102 (1): $131-66$.

Aghion, Philippe, Antoine Dechezleprêtre, David Hemous, Ralf Martin, and John Van Reenen. 2012. "Carbon Taxes, Path Dependency and Directed Technical Change: Evidence from the Auto Industry." NBER Working Papers.

Ambec, Stefan, Mark A. Cohen, Stewart Elgie, and Paul Lanoie. 2013. "The Porter Hypothesis at 20: Can Environmental Regulation Enhance Innovation and Competitiveness?" Review of Environmental Economics and Policy 7 (1): 2-22.

Antal, Miklós, and Jeroen C.J.M. van den Bergh. 2014. "Re-Spending Rebound: A MacroLevel Assessment for OECD Countries and Emerging Economies." Energy Policy 68: 585-90.

Baranzini, Andrea, and Stefano Carattini. 2014. "Taxation of Emissions of Greenhouse Gases.” In Global Environmental Change, edited by Bill Freedman, 543-60. Handbook of Global Environmental Pollution 1. Springer Netherlands.

Drews, Stefan, and Jeroen C. J. M. van den Bergh. forthcoming. "What Explains Public Support for Climate Policies? A Review of Empirical and Experimental Studies." Climate Policy

Fischer, Carolyn, and Richard G. Newell. 2008. "Environmental and Technology Policies for Climate Mitigation." Journal of Environmental Economics and Management 55 (2): 142-62.

Hoel, Michael. 1992. "Carbon Taxes : An International Tax or Harmonized Domestic Taxes?" European Economic Review 36 (2-3): 400-406.

Jaffe, Adam B., and Robert N. Stavins. 1995. "Dynamic Incentives of Environmental Regulations: The Effects of Alternative Policy Instruments on Technology Diffusion." Journal of Environmental Economics and Management 29 (3).

Nordhaus, William. 2015. "Climate Clubs: Overcoming Free-Riding in International Climate Policy." American Economic Review 105 (4): 1339-70.

Ostrom, Elinor. 2009. "A Polycentric Approach for Coping with Climate Change." Policy Research Working Paper Series. The World Bank.

Sanstad, Alan H., and Richard B. Howarth. 1994. "Normal' Markets, Market Imperfections and Energy Efficiency.” Energy Policy 22 (10): 811-18.

Sorrell, Steven. 2007. "The Rebound Effect: An Assessment of the Evidence for EconomyWide Energy Savings from Improved Energy Efficiency.” Project Report. UK Energy Research Centre.

van den Bergh, Jeroen C. J. M. 2011. "Energy Conservation More Effective With Rebound Policy." Environmental and Resource Economics 48 (1): 43-58.

. 2015. "Climate Summit: Pricing Would Limit Carbon Rebound." Nature 526 (7572): 195-195.

Weitzman, Martin L. 1974. "Prices vs. Quantities.” Review of Economic Studies 41 (4): 47791.

Wood, Peter John, and Frank Jotzo. 2011. "Price Floors for Emissions Trading.” Energy Policy 39 (3): 1746-53.

World Bank. 2014. "State and Trends of Carbon Pricing 2014.” World Bank Group. 
Cahiers de recherche du Centre de Recherche Appliquée en Gestion (CRAG) de la Haute Ecole de Gestion - Genève

\section{(C) 2015}

CRAG - Centre de Recherche Appliquée en Gestion

Haute école de gestion - Genève

Campus de Battelle, Bâtiment $\mathrm{F}$

7, route de Drize - 1227 Carouge - Suisse

$\triangle$ crag@hesge.ch

www.hesge.ch/heg/crag

(D) +41223881818

圆 +41223881740

Tous les cahiers de recherche de la HEG sur ArODES : http://goo.gl/zelhbn 